\title{
VIOLÊNCIA: UM PROBLEMA DE SAÚDE
}

Lourdete Rejane Ferro Zago ${ }^{1}$

\section{INTRODUÇÃO}

A violência é uma questão de saúde pública. Suas manifestações, em sua procedência constituem-se em um fenômeno sócio-histórico, tendo acompanhado a humanidade em seu percurso histórico, sendo realizado pelas pessoas, por grupos, pela cultura.

Marx (1867) define a violência como a parteira de uma sociedade mais antiga, trazendo em suas entranhas para a nova sociedade.

Para KRUG, DAHLBERG, MERCY, ZWI e LOZANO (2002) a violência, provavelmente sempre fez parte da experiência humana. Sua marca é deixada de várias formas, em todos os lugares do mundo. Estes autores informam que a cada ano, mais de um milhão de pessoas perdem a vida, sofrem lesões irreversíveis, como resultado de violência interpessoal, auto-infligida ou coletiva. Acrescentam ainda que em geral, a violência está entre as principais causas de morte no mundo para as pessoas com idade entre 15 a 44 anos.

Desta forma pode-se dizer que a violência é uma questão social, a qual transforma-se em um mote para a área da saúde, por afetar o indivíduo, a sociedade , necessitando portanto de prevenção e tratamento, o que conduz a formulação de políticas específicas e organizações práticas peculiares aos setores da saúde. A violência é uma questão de saúde porquanto afeta a qualidade de vida das pessoas, pelas lesões físicas, psíquicas, morais, que exigem cuidados dos serviços médicos e hospitalares. Além disso, porque afeta diretamente o conceito de saúde da Organização Mundial de Saúde (OMS) em 2010, "saúde é um estado dinâmico de completo bem-estar físico, espiritual, mental e social, e não apenas a ausência de doenças ou enfermidades".

De acordo com a OMS, os principais determinantes da saúde incluem o ambiente social e econômico, o ambiente físico e as características e comportamentos

\footnotetext{
${ }^{1}$ Licenciatura Plena em Enfermagem e Obstetrícia pela Faculdade de Enfermagem Nossa Senhora Medianeira (1984) e Mestrado em Filosofia pela Pontifícia Universidade Católica do Rio Grande do Sul (1996). Atualmente é Diretora da Faculdade Santa Clara. Tem experiência na área de Enfermagem, atuando principalmente em enfermagem e saúde pública.E-mail: zagovitoria2@gmail.com
} 
individuais da pessoa. Em geral, o contexto em que um indivíduo vive é de grande importância na sua qualidade de vida e em seu estado de saúde. $\mathrm{O}$ ambiente social e econômico são fatores essenciais na determinação do estado de saúde dos indivíduos dado o fato de que altos níveis educacionais estão relacionados com um alto padrão de vida, bem como uma maior renda.

No ano de 2010 a OMS lançou uma publicação com o título "Equity, social determinants and public health programmes" (Equidade, determinantes sociais e programas de saúde pública) renovando o desafio lançado em Setembro de 2008 pela apresentação do relatório da sua "Comissão para os Determinantes Sociais da Saúde".

Assim, a OMS estabelece que os determinantes sociais da saúde são as condições em que as pessoas nascem, crescem, vivem, trabalham e envelhecem, incluindo o sistema de saúde. Estas circunstâncias são formatadas pela distribuição da riqueza, poder e recursos a nível global, nacional e local, as quais são também influenciadas por decisões políticas. Os determinantes sociais da saúde são os principais responsáveis pelas desigualdades na saúde - as diferenças injustas e evitáveis no estado de saúde encontrado dentro e entre países. Esta publicação relaciona diversas condições de saúde-doença com determinantes sociais e propõe que a abordagem eficaz das iniquidades em saúde envolva novos conjuntos de intervenções. Como também propõe a modificação na forma como os programas de saúde pública são organizados e operam assim como uma redefinição do que constitui uma intervenção em saúde pública. Vários programas de saúde pública da OMS participaram neste trabalho que também reflete a contribuição de diversos eventos, comissões e relatórios da OMS.

KRUG, DAHLBERG, MERCY, ZWI e LOZANO (2002) ao elaborarem o Relatório Mundial sobre Violência e Saúde, tiveram como objetivos, a princípio ampliar a consciência a respeito da questão da violência em âmbito mundial. Para isto, o outro objetivo constituiu em argumentar que a violência pode ser prevenida e que a saúde pública exerce um papel de crucial importância ao reconhecer as causas e conseqüências da violência. Continuando com as metas a alcançar, os autores, neste relatório, descrevem: a magnitude e o impacto da violência em todo o mundo; descrevem os principais fatores de risco que causam a violência; relatam os tipos de ações, intervenções e respostas políticas que têm sido implantados resumindo o que se conhece sobre sua eficácia e recomendam ações em nível local, nacional e internacional. 
Diante isto, este artigo tem como objetivo estabelecer a relação da violência com a saúde, considerando esta área em âmbito geral, como compreendendo a pertinência da questão pública, para se concretizar esta relação.

Para tal intento, este artigo aborda a princípio concisamente a perspectiva histórica da violência

\section{A PERSPECTIVA HISTÓRICA DA VIOLÊNCIA}

O consenso geral é que a violência apareceu com a existência da humanidade.

Segundo Minayo e Souza (1999) a dificuldade em conceituar a violência, consiste primordialmente em sua forma própria de relação pessoal, política, social e cultural. Estas autoras acrescentam que pode ser resultado das interações sociais, como também, por ser um componente de determinada cultura. Elas comentam que toda a produção filosófica, mitológica e antropológica da humanidade confere à violência um caráter de permanência em todas as sociedades. Além disso, outra dificuldade que elas referem diz respeito à ambigüidade, considerada algumas vezes como fenômeno positivo, outras vezes como negativo, tornando-a um fenômeno complexo. Elas concluem que não há como reproduzir a verdade social e histórica, e os mitos e crenças a respeito da violência costumam distorcer a realidade como num "espelho invertido".

KRUG, DAHLBERG, MERCY, ZWI e LOZANO (2002) referem que não existe um fator único pelo qual forneça a explicação necessária do por que algumas pessoas se comportam de forma violenta em relação a outras, ou porque a violência ocorre mais em algumas comunidades do que em outras. Para eles a violência consiste no resultado de uma interação complexa de fatores individuais, sociais, culturais e ambientais. Eles acreditam que para evitar a violência a partir de uma abordagem da saúde pública, torna-se necessário compreender como estes fatores se relacionam com a violência.

Vanier (2004) citando Freud

Inicialmente, numa pequena horda humana, era a força muscular maior que decidia a quem alguma coisa devia pertencer ou quem veria sua vontade executada, pela superação da violência por meio da transferência de poder para uma unidade maior [...]abre mão de uma parte de sua própria segurança [...] O direito da comunidade se torna, então, a expressão das relações desiguais de poder que existem em seu 
seio, as leis serão feitas pelos que dominam e para os que dominam (VANIER, 2004 p 2)

Desta forma, conforme Varnier(2004) originalmente a lei se impunha pela força física, dirigida por uma vontade que se aplica a outro, tanto como um objeto, ou a outro enquanto objeto. Para ele o poder nascia do desenvolvimento e do deslocamento da força corporal. Só muito mais tarde é que a paz social pôde se organizar. Quando o grupo dominante substitui o ato de matar pelo de escravizar. O corpo do outro pode servir aos interesses econômicos de quem impõe sua lei. Desta maneira, o vencido, vivo, constitui uma ameaça. A estabilidade legal e a tranquiilidade que ela produz só podem ser obtidas com a substituição da relação entre vencedor e vencido pela relação entre senhor e escravo. Ele conclui então que logo, a paz contém a guerra como seu fundamento e nada mais é que a expressão de uma violência coletiva imposta pelos vencedores aos vencidos, a expressão de uma violência de poder.

Ainda nesta perspectiva este autor considera que cria-se uma comunidade organizada fundamentalmente pela coação e cuja coesão está garantida por fenômenos de identificação, percebidos como sentimentos. Esta violência que desapossou o vencido e que assegura a base da tranqüilidade social obriga o vencedor, para sua própria segurança, a repor em circulação um pouco do que ganhou para manter vivos os corpos dos escravos. Seu capital, a fim de estes possa aumentar ainda mais a quantidade de bens que o vencedor possui. De certo modo, esta paz social é uma guerra que repete incansavelmente a pilhagem original por meio da violência que se abate sobre o vencido. Com efeito, este último não cessa de ser despojado daquilo que lhe cabe e do que produz.

\section{A NATUREZA MULTIFACETADA DA VIOLÊNCIA.}

KRUG, DAHLBERG, MERCY, ZWI e LOZANO (2002) comentam que no mundo todo, a violência invade a vida de muitas pessoas e, de alguma maneira, toca a todos nós. Para muitas pessoas, ficar a salvo é questão de trancar portas e janelas e evitar lugares perigosos. Para outros, é impossível escapar. A ameaça da violência está atrás dessas portas, bem escondida da vista pública. 
E, para aqueles que vivem no meio de guerras e conflitos, a violência permeia todos os aspectos da vida.

Arendt (1990) ao refletir sobre a violência considera que nenhum historiador pode ficar alheio ao imenso papel que a violência sempre desempenhou nos assuntos humanos, preocupando sobre o fato de existirem poucos estudos a este respeito. Para este autor a violência tem um caráter instrumental, ou seja, é um meio que necessita de orientação e justificação dos fins que persegue.

Eles referem que existem vários níveis a considerar ao refletir a respeito da violência.

Eles consideram que introduzido pela primeira vez ao final da década de 1970, este modelo ecológico foi inicialmente aplicado ao abuso infantil e, posteriormente, à violência juvenil. Eles complementam que mais recentemente, os pesquisadores têm usado esse modelo para entender a violência praticada pelo parceiro íntimo e o abuso contra os idosos

Esse modelo ecológico, conforme estes autores, explora a relação entre fatores individuais e contextuais e considera a violência como o resultado de vários níveis de influência sobre o comportamento.

Eles descrevem inicialmente o nível individual. Busca identificar os fatores históricos - biológicos e pessoais - que uma pessoa traz em seu comportamento. Além dos fatores biológicos e demográficos, são levados em consideração outros fatores tais como impulsividade, baixo rendimento escolar, abuso de substâncias [tóxicas] e histórico de agressão e abuso. Em outras palavras, este nível do modelo ecológico se concentra nas características da pessoa que aumentam a possibilidade de ela ser uma vítima ou um perpetrador da violência.

Os autores descrevem também o nível Racional, o qual explora como as relações sociais próximas - relações com companheiros, parceiros íntimos e membros da família - aumentam o risco para vitimização violenta e perpetração da violência. Nos casos de violência de parceiro e maus tratos à criança, por exemplo, a interação quase diária ou o convívio em uma casa com alguém que pratique abuso podem aumentar a oportunidade de confrontos violentos. Eles comentam que como as pessoas são obrigadas a um relacionamento contínuo, é provável que, nesses casos, a vítima sofra repetidos abusos praticados pelo criminoso. 
No caso de violência interpessoal entre jovens, Krug, Dahlberg, Mercy, Zwi e Lozano (2002) as pesquisas mostram que jovens têm maior probabilidade de entrar em atividades negativas quando tais comportamentos são incentivados e aprovados pelos amigos. Os companheiros, parceiros íntimos e membros da família têm poder para moldar o comportamento de uma pessoa e a sua esfera de experiências.

Chesnais (1999) refere que a violência, sobretudo urbana, está no centro do dia a dia e ocupa as manchetes dos jornais. Ela é assunto de especiais para a mídia e, mais que tudo, assombra as consciências, de tal forma é ameaçadora, recorrente e geradora de um profundo sentimento de insegurança. Para ele reflete a desintegração social, de um mal-estar coletivo e de um desregramento das instituições públicas.

Este autor comenta que a violência oculta atrás dos muros das casas, a violência sexual, as rixas familiares e as crianças espancadas só são conhecidas muito parcialmente, mesmo em caso de falecimento das vítimas. Ele conclui que as circunstâncias das mortes são, então, esmagadas sob uma capa de silêncio, pois o controle pelo registro civil continua a ser falho, principalmente nas zonas rurais mais pobres ou dentro de zonas urbanas de instalação recente (subúrbios, favelas e cortiços).

Qualquer análise abrangente da violência deve começar pela definição das várias formas de violência, de modo a facilitar sua mensuração científica, conforme diversos autores (Chesnais,1999; Minayo e Souza, 1999; Krug, Dahlberg, Mercy, Zwi e Lozano,2002; Budó, Mattioni, Machado, Ressel, Borges, Newlands, 2007). Para estes autores existem várias maneiras de se definir a violência.

A Organização Mundial da Saúde define violência como o uso intencional da força física ou do poder, real ou em ameaça, contra si próprio, contra outra pessoa, contra um grupo, uma comunidade, que resulte tendo grande possibilidade de resultar em lesão, morte, dano psicológico, deficiência de desenvolvimento ou privação.

A definição utilizada pela Organização Mundial da Saúde associa intencionalidade com a prática do ato propriamente dito, independentemente do resultado produzido. Os incidentes não intencionais - tais como a maioria das lesões de trânsito e queimaduras acidentais - estão excluídos da definição.

A inclusão da palavra "poder", além da frase "uso da força física", amplia a natureza de um ato violento e expande o entendimento convencional de violência de 
modo a incluir aqueles atos que resultam de uma relação de poder, inclusive ameaças e intimidações, de acordo com Krug, Dahlberg, Mercy, Zwi e Lozano (2002).

Para estes autores o "uso do poder" também serve para incluir negligência ou atos de omissão, além de atos violentos mais óbvios de perpetração. Assim, "o uso da força física ou do poder" deve ser entendido de forma a incluir a negligência e todos os tipos de abuso físico, sexual e psicológico, bem como o suicídio e outros atos de autoabuso.

Essa definição cobre uma ampla gama de conseqüências, na opinião destes autores, incluindo dano psicológico, privação e deficiência de desenvolvimento. Para eles a violência reflete um reconhecimento cada vez maior por parte dos pesquisadores e profissionais acerca da necessidade de incluir a violência que não resulta necessariamente em lesões ou morte, mas que, contudo, oprime as pessoas, as famílias, as comunidades e os sistemas de assistência à saúde no mundo todo.

Para vários autores (Krug, Dahlberg, Mercy, Zwi e Lozano,2002; Chesnais,1999; Budó, Mattioni, Machado, Ressel, Borges, Newlands, 2007; Minayo, 2003) entre outros, muitas formas de violência contra mulheres, crianças e idosos, por exemplo, podem resultar em problemas físicos, psicológicos e sociais que não necessariamente levam a lesões, invalidez ou morte. Estes autores referem que essas conseqüências podem ser imediatas, bem como latentes, e podem perdurar por anos após o abuso inicial. Portanto, definir os resultados somente em termos de lesões ou mortes limita a compreensão da totalidade do impacto da violência sobre as pessoas, as comunidades e a sociedade como um todo.

De acordo com Krug, Dahlberg, Mercy, Zwi e Lozano (2002) a intencionalidade consiste em um dos aspectos mais complexos da definição de violência.Eles comentam que dois aspectos devem ser considerados. Em primeiro lugar, mesmo a violência sendo distinta de eventos não intencionais que resultam em lesões, a presença de uma intenção de usar a força não necessariamente significa que houve uma intenção de causar dano.

Eles consideram que pode haver uma grande disparidade entre 0 comportamento pretendido e a conseqüência pretendida. Um perpetrador pode cometer intencionalmente um ato que, por padrões objetivos, é considerado perigoso e com alta 
possibilidade de resultar em efeitos adversos à saúde, mas o perpetrador pode não perceber seu ato dessa forma.

Eles exemplificam: um jovem pode envolver-se em uma briga com outro jovem. Dar um soco contra a cabeça ou usar de uma arma na briga certamente aumentam o risco de uma lesão grave ou morte, apesar de não haver intenção de nenhum desses resultados. Um pai ou uma mãe pode sacudir com violência uma criança que esteja chorando tentando fazê-la calar.

Contudo, eles concluem esse ato pode causar danos cerebrais. É claro que a força foi usada, mas sem a intenção de causar uma lesão.

Um segundo ponto relacionado à intencionalidade de acordo com estes autores, reside na distinção entre a intenção de lesar e a intenção de "usar a violência". A violência, de acordo com Walters \& Parke (1964), é determinada culturalmente.

Algumas pessoas tencionam ferir os outros, mas, com base em seus antecedentes culturais e suas crenças, não percebem seus atos como violentos, na opinião de Krug, Dahlberg, Mercy, Zwi e Lozano (2002).

A definição utilizada pela Organização Mundial da Saúde, contudo, define a violência em relação à saúde ou ao bem-estar das pessoas. Determinados comportamentos, como bater na esposa, podem ser considerados por algumas pessoas como práticas culturais aceitáveis, mas são considerados atos violentos, com importantes implicações para a saúde da pessoa.

Para Krug, Dahlberg, Mercy, Zwi e Lozano (2002) as mulheres que são vítimas de abuso por parte de seus parceiros têm mais depressão, ansiedade e fobias do que as mulheres que não sofrem nenhum tipo de abuso. Pesquisa indicam ainda que as mulheres que foram vítimas de abuso praticado por seus parceiros estão sob risco muito maior de suicídio e tentativas de suicídio

Outros aspectos da violência, apesar de não estarem explicitamente colocados, também se encaixam na definição. Por exemplo, a definição implicitamente inclui todos os atos de violência, sejam públicos e privados, sejam reativos (em resposta a eventos anteriores, como provocações) proativos (instrumental para resultados em benefício próprio, com intenção de tal benefício) sejam atos criminosos ou não criminosos. Cada um desses aspectos é importante para se compreender as causas da violência e elaborar programas de prevenção (KRUG, DAHLBERG, MERCY, ZWI E LOZANO, 2002). 
Para estes autores a violência praticada por parceiros íntimos consiste em um importante problema de saúde pública. Eles consideram que para resolver esse problema é necessário o envolvimento de diversos setores trabalhando em conjunto nos níveis comunitário, nacional e internacional. Em cada nível, as respostas devem incluir dar poder às mulheres e às jovens, conseguir envolver os homens, dar assistência às necessidades das vítimas e aumentar as sanções para quem pratica o abuso. É crucial que as respostas envolvam crianças e jovens e tenham como foco a mudança das normas comunitárias e sociais. Assim eles concluem que o progresso feito em cada uma dessas áreas será a chave para se conseguir reduções mundiais na violência contra parceiros íntimos.

No que diz respeito à violência com crianças vários autores discutem a relação direta com os serviços públicos de saúde (Krug, Dahlberg, Mercy, Zwi e Lozano,2002; Chesnais,1999; Budó, Mattioni, Machado, Ressel, Borges, Newlands, 2007; Minayo, 2003). Para eles o abuso infantil, é um problema sério de saúde mundial. Eles referem que embora a maior parte dos estudos relativos ao assunto tenha sido conduzida em países desenvolvidos, é um fenômeno comum em todo o mundo. Muito mais pode e deve ser feito em relação ao problema. Em muitos países, o reconhecimento do abuso infantil entre os profissionais da área pública ou da saúde é muito restrito. O reconhecimento e a conscientização, embora sejam elementos essenciais para uma prevenção eficaz, são apenas parte da solução. Os esforços e as políticas de prevenção devem voltar-se diretamente para as crianças, para as pessoas responsáveis pelas mesmas e para o meio ambiente em que vivem, a fim de evitar que ocorram abusos futuros e lidar de maneira eficaz com casos de abuso e negligência que tenham ocorrido. Nesse caso, são necessários esforços combinados e coordenados de uma série de setores, e os pesquisadores e especialistas da saúde pública podem desempenhar um papel extremamente importante no que toca à liderança e facilitação do processo.

Como também é um problema de saúde pública a violência contra idosos. Minayo (2003) e Krug, Dahlberg, Mercy, Zwi e Lozano (2002) consideram que O problema do abuso de idosos não pode ser solucionado adequadamente se as necessidades essenciais dos idosos - de alimentação, abrigo, segurança e acesso à assistência à saúde - não forem atendidas. As nações do mundo devem criar um ambiente em que envelhecer seja aceito como uma parte natural do ciclo da vida, em 
que atitudes antienvelhecimento sejam desencorajadas, em que os idosos tenham o direto de viver com dignidade, livres de abusos e exploração, e seja dada a eles a oportunidade de participar plenamente das atividades educacionais, culturais, espirituais e econômicas

\section{CONCLUSÃO}

A saúde pública deve se interessar pela saúde e bem-estar das populações como um todo. Considerando que a violência impõe uma carga pesada no bem-estar da população. Um dos objetivos da saúde pública deve ser o de criar comunidades seguras e sadias em todo o mundo. A prioridade maior, atualmente, consiste em persuadir todos os diversos setores - a nível global, nacional e comunitário - a se comprometer com tal objetivo. As autoridades da saúde pública necessitam fazer muito para estabelecer planos e políticas nacionais para prevenir a violência, realizando parcerias entre os vários setores e assegurando dotação de recursos para as ações preventivas.

Embora a liderança da saúde pública não precise e não possa dirigir todas as ações para prevenir e reagir à violência, as autoridades e líderes têm um papel relevante nesse âmbito. Os dados existentes no acervo da saúde pública e outras agências, as visões e a compreensão obtidas por intermédio do método científico e a dedicação no sentido de encontrar respostas verdadeiras são contribuições importantes que a área da saúde pública faz às reações globais contra a violência.

\section{REFERÊNCIAS}

1. ARENDT, A 1990. As Origens do Totalitarismo. Companhia das Letras, São Paulo

2. BUDÓ, Maria de Lourdes Denardin; MATTIONI Fernanda Carlise ; MACHADO, Tiago da Silva'; RESSEL Lúcia Beatriz ; BORGES, Zulmira Newlands 2007. Concepções de violência e práticas de cuidado dos usuários da estratégia de saúde da família: uma perspectiva cultural. Texto contexto enferm. vol.16 no.3 Florianópolis July/Sept. 2007 
3. CHESNAIS, Jean Claude.1999 A violência no Brasil. Causas e recomendações políticas para a sua prevenção Ciênc. saúde coletiva vol.4 no.1 53-69.

4. KRUG, Etienne G., DAHLBERG Linda L.; MERCY, James A., ZWI Anthony B. e LOZANO Rafael. (2002) World report on violence and health. World Health

5. MINAYO, Maria Cecília de Souza e SOUZA, Edinilsa Ramos 1999 É possível prevenir a violência? Reflexões a partir do campo da saúde pública. Ciência Saúde Coletiva vol.4 № 1 p 7-23

6. VANIER, Alain (2004) Direito e Violência. Ágora: Estudos em Teoria Psicanálitica. Vol 7 n 1 p129-141

7. MORAIS, Sheila Coelho Ramalho Vasconcelos; MONTEIRO, Claudete Ferreira de Sousa; ROCHA Silvana Santiago.2010 O cuidar em enfermagem à mulher vítima de violência sexual. Texto contexto - enfermagem. vol.19 no.1

8. MINAYO, Maria Cecília de Souza .2003. Violência contra idosos: relevância para um velho problema Cad. Saúde Pública, Rio de Janeiro, 19(3):783-791,

9. Walters RH, Parke RD. Social motivation, dependency, and susceptibility to social influence. In: Berkowitz L. Advanceds in experimental social psychology. v. 1. New York, NY: Academic Press; 1964. p. 231-76 